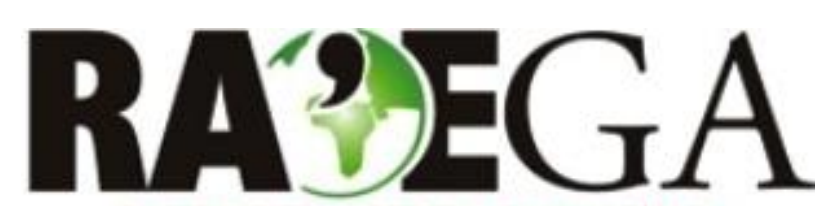

O ESPAÇO GEOGRÁFICO EM ANÁLISE

\title{
FRONTEIRA AGRÍCOLA E A ANÁLISE DA ESTRUTURA DA PAISAGEM NA BACIA DO RIO PRETO - OESTE DA BAHIA
}

\section{FRONTIER AGRICULTURAL AND ANALYSIS OF LANDSCAPE STRUCTURE IN BASIN OF RIO PRETO - WESTERN BAHIA}

\author{
Crisliane Aparecida Pereira Santos \\ Universidade do Estado da Bahia \\ Salvador, BA, Brasil \\ e-mail: crislianeaparecida@hotmail.com
}

Edson Eyji Sano

Embrapa Cerrados

Brasília, DF, Brasil

e-mail: edson.sano@gmail.com

Pablo Santana Santos

Universidade Federal da Bahia

Salvador, BA, Brasil

e-mail:pablosantos@ufba.br

\section{Resumo}

Em áreas de Cerrado a expansão da fronteira agrícola tem sido a principal causa de fragmentação da paisagem. Este artigo tem como objetivo analisar a estrutura espacial da paisagem da bacia hidrográfica do Rio preto, por meio da construção de um índice de qualidade estrutural da paisagem, ao longo destes trinta anos de ocupação. Para a determinação do estado da fragmentação dos remanescentes naturais, avaliou-se previamente o padrão de uso e ocupação do solo na bacia durante o período de 1980 a 2010, e em seguida determinouse as métricas da paisagem por meio da extensão Path Analyst 5.0, que por seguinte, serviu de base para construção de um modelo de qualidade ambiental da paisagem, o IQEP. Os resultados mostraram que o processo da fronteira agrícola no Oeste da Bahia, a partir de 1985, provocou significativas mudanças na estrutura da paisagem ao longo do tempo e do espaço. As sub- 
bacias Baixo Curso e Rio Sapão apresentaram forte correlação positiva com TCAI, TCA, PSSD, MPS e CA, ou seja, consideradas de melhor qualidade estrutural. Já as sub-bacias Rio Riachão e Rio do Ouro apresentaram significativo comprometimento do padrão estrutural, mediante a redução do IQEP, com susceptibilidade à fragmentação da paisagem, em função da maior contribuição do efeito da borda sob a área central do fragmento.

Palavras chave: uso e ocupação do solo; fragmentação da paisagem; índice de qualidade estrutural da paisagem.

\begin{abstract}
In Cerrado areas the expansion of the agricultural frontier has been the leading cause of habitat fragmentation. This article aims to analyze the spatial structure of the landscape of the basin of the Rio Preto, through the construction of a structural landscape quality index, over these thirty years of occupation. To determine the state of fragmentation of remaining natural, it was previously evaluated the pattern of land use and occupation in the basin during the period from 1980 to 2010, and then was determined the landscape metrics by extending Path Analyst 5.0, which in the following, was the basis for building an environmental quality model of the landscape, the IQEP. The results showed that the process of the agricultural frontier in the Western Bahia, from 1985, caused significant changes in the landscape structure over time and space. The Baixo Curso and Rio Sapão sub-basins showed a strong positive correlation with TCAI, TCA, DSSP, MPS and CA, that is, considered better structural quality. As for the sub-basins Rio Riachão and Rio do Ouro showed significant impairment of structural pattern by reducing the IQEP with susceptibility to habitat fragmentation, due to the higher contribution of the edge effect under the central area of the fragment.
\end{abstract}

Keywords: use and land use; landscape fragmentation; structural landscape quality index.

\title{
1. INTRODUÇÃO
}

O marco pioneiro da fragmentação de paisagens, em biomas brasileiros, data do período colonial, quando da chegada da colônia portuguesa em território da Mata Atlântica. Em áreas de Cerrado, a expansão da fronteira agrícola, orientada pela agricultura moderna, tem sido a principal causa de desmatamento (GASPARRI; GRAU, 2009), resultando em um crescente processo de fragmentação da paisagem (TURNER, 2005).

Desde a década de 1980, a fronteira agrícola no Cerrado baiano vem ocupando áreas planas, de maior intensidade pluviométrica e em solos com R. Ra'e Ga - Curitiba, v. 36, p.179 - 207 , Abr/2016 


\section{FRONTEIRA AGRÍCOLA E A ANÁLISE DA ESTRUTURA DA PAISAGEM NA BACIA DO RIO PRETO} - OESTE DA BAHIA

potencial produtivo, tornando-se um grande celeiro de produção agrícola. Isto implica em dizer que as mudanças na paisagem pela ação humana não são aleatórias, mas pautadas mediante interações entre fatores socioeconômicos e fisiográficos (FORMAN; COLLINGE, 1997).

$\mathrm{Na}$ Bacia Hidrográfica do Rio Preto (BHRP), situação idêntica foi observada, cuja área é considerada o novo polígono de expansão da fronteira agrícola. De acordo com Vale e Reis (2012) Formosa do Rio Preto é o município cuja atividade agropecuária é dominante no setor econômico, com participação de $11,4 \%$ no PIB do Oeste da Bahia, sobretudo pela soja, que apresentou, em 2008, uma produção de 461.472 t a partir de 152.000 ha plantadas. Entretanto, associado ao crescimento econômico, Formosa do Rio Preto também é o município que mais desmatou (taxa de 2,7\%/ano) de acordo o mapeamento do bioma Cerrado realizado durante o período de 2008 - 2009 (IBAMA, 2009).

A fragmentação da paisagem "é um processo de mudanças na escala espacial importante na evolução e conservação [...] que pode ser causada tanto por processos naturais, quanto por processos antrópicos" (CORRÊA; LOUZADA, 2010 p. 59). Ou, como um processo pelo qual determinada área contínua sofre redução do tamanho do habitat original e se separa em dois ou mais fragmentos, de tamanhos reduzidos e isolados entre si (CABACINHA; CASTRO, 2009; WALZ, 2011).

Cada paisagem é resultado de diferentes elementos físicos, biológicos e antrópicos que interagem entre si (BERTRAND, 1968), onde o "todo" torna-se muito maior que a simples soma das partes (TROL, 1971). Sendo a paisagem o resultado de uma evolução por combinação dinâmica dos elementos de fatores geológicos, processos fisiográficos, climáticos e temporais (PÉRICO; CEMIN, 2006; WILSON et al., 2009).

A utilização de dados de Sensoriamento Remoto permite realizar esta análise espacial da paisagem, por meio da descrição quantitativa da configuração complexa da paisagem (MYAMOTO; SANO, 2009). E a integração e a combinação destes diferentes elementos tornam-se factíveis por 


\section{FRONTEIRA AGRÍCOLA E A ANÁLISE DA ESTRUTURA DA PAISAGEM NA BACIA DO RIO PRETO} - OESTE DA BAHIA

meio de técnicas de Sistema de Informação Geográfica (SIG) (BLASCHKE, 2009, p. 146), pois sendo a paisagem uma área multidimensional (horizontal, vertical e multiespectral), ou de heterogeneidade espacial, favorece a sua aplicação nos estudos da dinâmica dos processos ecológicos (TROLL, 1971; FORMAN; GODRON, 1986), além de mapear variações ambientais no tempo e no espaço em diferentes habitats (SHAO; WU, 2008).

A análise da fragmentação da paisagem é realizada segundo a presença de padrões espaciais (METZGER; DECAMPS, 1997; WALZ, 2011). Para quantificar os padrões espaciais da paisagem, uma variedade de métricas ou índices da paisagem é necessária para avaliar o efeito da fragmentação em diferentes escalas espaciais e temporais (FERRAZ et al., 2005; TURNER, 2005; SANO et al., 2009). Este conjunto de métricas permite realizar uma análise do histórico da fragmentação em áreas de remanescentes naturais (CABACINHA; CASTRO, 2009; GOULART et al., 2013), com vistas a compreender a relação entre o padrão espacial da paisagem e os processos ecológicos (GUSTAFSON; PARKER, 1992), permitindo caracterizar o nível de fragmentação espacial da paisagem (PÉRICO; CEMIN, 2006).

Fatores como área, forma, histórico da perturbação, tipo de vizinhança e isolamento dos fragmentos podem alterar a dinâmica e a estrutura de fragmentos naturais (FORMAN, 1995; TURNER, 2005; WILSON et al., 2009). Com relação à estrutura espacial da paisagem, a intensificação do uso e ocupação do solo pela agricultura produz paisagens relativamente mais simples, de menor complexidade, seguida da redução de perda de área natural e de biodiversidade, além de diminuir a redução da permeabilidade de organismos que habitam estas áreas e que, quando associada à perda da complexidade da paisagem, afeta negativamente sua riqueza e diversidade (GOULART et al., 2013).

Além das alterações das fitofisionomias naturais, outro efeito muito comum é a formação de novas bordas e a modificação das bordas préexistentes (ASBJORNSEN et al., 2004). Por esta razão, o monitoramento 
contínuo da paisagem ao longo de um processo de perturbação torna-se de grande importância (FERRAZ et al., 2007).

Com vistas a demonstrar o efeito da conversão de áreas naturais em atividades agropecuárias sobre a estrutura da paisagem no Cerrado baiano, objetivou-se analisar a estrutura espacial da paisagem da BHRP, por meio da construção de um índice de qualidade estrutural da paisagem, ao longo destes trinta anos de ocupação, defendendo a hipótese de que o avanço antrópico da fronteira agrícola afetou negativamente a qualidade da paisagem.

\section{MATERIAIS E MÉTODOS}

\subsection{Caracterização da área de estudo}

A BHRP está totalmente inserida na mesorregião Oeste da Bahia (Figura 1) e apresenta uma área de drenagem de $22.382 \mathrm{~km}^{2}$, ocupando assim boa parte setentrional da bacia do rio Grande (afluente da margem esquerda da bacia do São Francisco), cujos domínios integram os municípios de Formosa do Rio Preto, Mansidão e Santa Rita de Cássia, que, em área total, chegam a possuir $25.559,5 \mathrm{~km}^{2}$, valores bem próximos à área da bacia (VALE; REIS, 2012).

Em relação à cobertura vegetal, a bacia contempla fragmentos de diversas fitofisionomias, salientando-se as Mata de Galeria, Mata Ciliar, Vereda e Cerrado. Além de Florestas Estacionais (Decídua e Semidecídua) e formações vegetacionais da Caatinga no médio e baixo curso da bacia (VALE; REIS, 2012). 

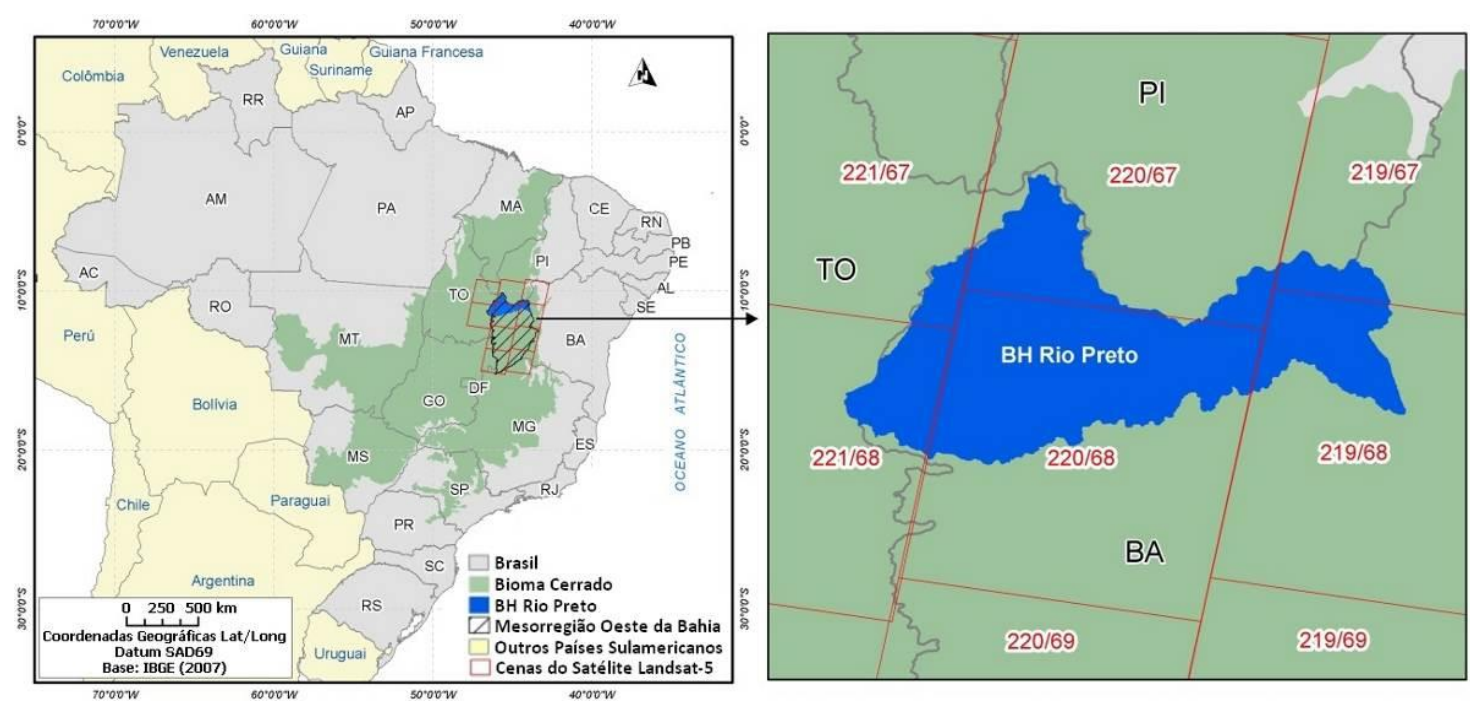

Figura 1 - Mapa de localização da área de estudo, com suas respectivas cenas do satélite TM - Landsat 5.

Apresenta como principais afluentes os rios Sapão, do Ouro, Riachão, entre outros. Os solos predominantes são classificados como Latossolos Vermelho-Amarelo, Argissolos, Neossolos Litólicos, Neossolos Quartzarênicos e Gleissolos. E a precipitação anual varia de $800 \mathrm{~mm}$ a $1.600 \mathrm{~mm}$, com os maiores valores localizados na porção extremo oeste e reduzindo à medida que se avança para o leste da bacia (ALVES et al., 2011).

\subsection{Metodologia}

Séries multitemporais da imagem de satélite TM - Landsat 5 (1980, 1990, 2000 e 2010) foram utilizadas para avaliar o padrão de uso e ocupação do solo na bacia. A elaboração dos mapas de uso e ocupação do solo da BHRP, para cada ano de análise, requereu as cenas 219/68, 219/67, 220/67, 220/68, 221/67 e 221/68. As classificações de 1980 a 2000 foram disponibilizadas por Sano et al. (2011), enquanto que a de 2010 se fez necessária a sua realização, devido às mudanças ocorridas no uso do solo.

O processamento digital das imagens (PDI) foi realizado segundo a metodologia aplicada por Sano et al. (2011), cujas imagens foram georreferenciadas no sistema de projeção cartográfica Universal Transversa de 
Mercator (UTM) e datum SAD 69, fuso 23S. Finalizada a correção geométrica, realizou-se o "mosaico" das imagens utilizando a técnica de equalização de histogramas. A classificação das imagens foi realizada por interpretação visual, mediante a identificação de feições nas respectivas imagens de satélite com composição colorida RGB, numa escala fixa de 1:60.000, o que resultou em quatro classes pré-definidas de uso e ocupação do solo: cultura agrícola, pastagem cultivada, reflorestamento e vegetação natural.

Uma vez realizada a classificação das imagens, efetuou-se o mapeamento dos fragmentos naturais, ortofotomosaico, dos anos de 1980, 1990, 2000 e 2010 recortando-os com base nos limites da BHRP e suas subbacias (Figura 2).

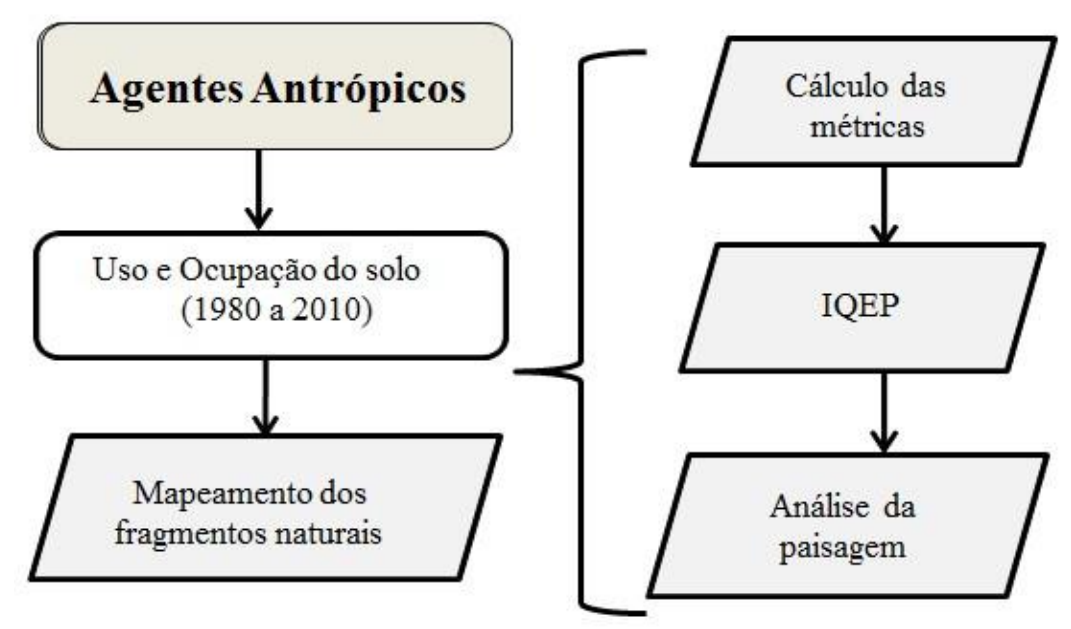

Figura 2 - Fluxograma da metodologia adotada.

Para a determinação do estado da fragmentação dos remanescentes naturais usaram-se métricas da paisagem na área de estudo. As métricas ou os índices de paisagem foram obtidos por meio da extensão Path Analyst 5.0, disponibilizado para o software ArcGIS 9.3 que, segundo Lang e Blaschke (2009), fornece as métricas do FRAGSTAT, porém, de maneira compacta.

Utilizou-se a versão para dados vetoriais com base nos arquivos de fragmentos naturais categorizados na etapa anterior, tanto para nível de 
paisagem, quanto de classe individual da paisagem da BHRP. O detalhamento das métricas analisadas encontra-se na Tabela 1.

Tabela 11- Descrição das principais métricas utilizadas para análise da estrutura espacial da paisagem da bacia segundo as contribuições de McGarigal e Marks (1995) e Lang e Blaschke (2009).

\begin{tabular}{|c|c|c|}
\hline Métrica & $\begin{array}{l}\text { Aspecto } \\
\text { principal }\end{array}$ & Observação \\
\hline CA (ha) & Métrica de área & $\begin{array}{l}\text { Área da classe. Quantificam a área de todos os } \\
\text { fragmentos da classe. Redução de valores } \\
\text { implica em alteração da matriz. }\end{array}$ \\
\hline $\begin{array}{c}\mathrm{NP} \\
\text { (adimensional) }\end{array}$ & Heterogeneidade & $\begin{array}{l}\text { Número de fragmentos. Grande número de } \\
\text { fragmentos indica maior fragmentação da classe, } \\
\text { podendo indicar também riqueza estrutural em } \\
\text { casos de baixa fragmentação. }\end{array}$ \\
\hline MPS (ha) & Métrica de área & $\begin{array}{l}\text { Tamanho médio do fragmento nas respectivas } \\
\text { classes. }\end{array}$ \\
\hline PSSD (ha) & Métrica de área & $\begin{array}{l}\text { Desvio padrão do tamanho médio do fragmento. } \\
\text { Expressa a variação do tamanho do fragmento. }\end{array}$ \\
\hline $\begin{array}{l}\mathrm{MSI} \\
\text { (adimensional) }\end{array}$ & Métrica de forma & $\begin{array}{l}\text { Índice médio de forma. Valore próximos a } 1 \\
\text { representam forma circular. }\end{array}$ \\
\hline $\begin{array}{l}\text { MPFD } \\
\text { (adimensional) }\end{array}$ & Métrica de forma & $\begin{array}{l}\text { Dimensão fractal média. Demonstra a } \\
\text { complexidade ou irregularidade do fragmento, } \\
\text { com valores variando de } 1 \mathrm{a} 2 \text {. }\end{array}$ \\
\hline TE $(m)$ & Métrica de borda & $\begin{array}{l}\text { Soma de todas as bordas das classes ou da } \\
\text { paisagem. Valores menores implicam em menor } \\
\text { influência de borda. }\end{array}$ \\
\hline ED (m/ha) & Métrica de borda & $\begin{array}{l}\text { Densidade de bordas. Valores altos podem } \\
\text { significar maior influência de borda. }\end{array}$ \\
\hline TCA (ha)* & $\begin{array}{l}\text { Métrica } \\
\text { central }\end{array}$ & $\begin{array}{l}\text { Área central total. Revela o tamanho da área } \\
\text { central por meio da soma de todas as classes. }\end{array}$ \\
\hline TCAI $(\%)^{*}$ & $\begin{array}{l}\text { Métrica } \\
\text { central }\end{array}$ & $\begin{array}{l}\text { Índice de área central total. Indica qual o } \\
\text { percentual do fragmento ocupado pela área } \\
\text { central. }\end{array}$ \\
\hline
\end{tabular}

* Para a determinação das métricas de área central delimitou-se um buffer de $100 \mathrm{~m}$ de largura da borda.

A fim de caracterizar a estrutura da paisagem da BHRP foi construído, neste trabalho, um modelo de qualidade ambiental da paisagem para as subbacias hidrográficas, denominado de Índice de Qualidade Estrutural da Paisagem (IQEP). A principal premissa deste modelo é que, quanto mais forte for a remoção do habitat natural, maior será a intensidade da fragmentação e 
menor será a qualidade ambiental da bacia, ou seja, maior o comprometimento da estrutura da paisagem.

O IQEP foi desenvolvido por meio dos resultados das 10 métricas aplicadas na análise da estrutura da paisagem, fixando-se pesos $(w)$ para cada métrica analisada, distribuídos em função da importância e do comportamento de cada métrica analisada para a conformação do estado da qualidade ambiental. A ponderação das métricas se fez necessária ao observar a existência de padrões de respostas distintos na paisagem. Os referidos pesos encontram-se na Tabela 2. O cálculo do IQEP foi obtido mediante o produto dos resultados com a ponderação de pesos para cada métrica conforme a equação elaborada abaixo:

$$
\begin{gathered}
\operatorname{IQEP}=\sum_{\mathrm{i}=1}^{\mathrm{n}}(1 \mathrm{qi} . \mathrm{W} ; 2 \mathrm{qi} . \mathrm{W} ; \ldots ; 10 \mathrm{qi} \cdot \mathrm{W}) \\
\sum_{\mathrm{i}=1}^{\mathrm{n}} w i=1
\end{gathered}
$$

sendo: IQEP = índice de qualidade estrutural da paisagem, com valores entre 0 e 1 ;

$$
\begin{aligned}
\mathrm{n} & =\text { número de métricas utilizadas no cálculo do índice; } \\
\text { qi } & =\text { resultado da i-ésima métrica } \\
\mathrm{w}_{\mathrm{i}} & =\text { peso da i-ésima métrica fixada em função de sua importância } \\
\text { ambiental, } & \text { com valores entre } 0 \text { e } 1 .
\end{aligned}
$$

Tabela 2- Pesos atribuídos às métricas para inserção no modelo IQEP.

\begin{tabular}{cc}
\hline Métrica & Peso $(\boldsymbol{w})$ \\
\hline CA & 0,15 \\
NP & 0,03 \\
MPS & 0,13 \\
PSSD & 0,03 \\
MSI & 0,03 \\
\hline
\end{tabular}

R. Ra'e Ga - Curitiba, v. 36, p.179 - 207 , Abr/2016 


\begin{tabular}{cc}
\hline MPFD & 0,03 \\
TE & 0,03 \\
ED & 0,17 \\
TCA & 0,15 \\
TCAI & 0,25 \\
\hline
\end{tabular}

O IQEP serviu como análise comparativa da qualidade ambiental entre as sub-bacias hidrográficas, para cada período analisado, sendo que valores próximos a 1 indicam boa qualidade estrutural da paisagem e valores próximo a 0 implicam de baixa qualidade estrutural.

\section{RESULTADOS E DISCUSSÃO}

\subsection{Análise multitemporal da dinâmica do uso e ocupação do solo da BHRP}

A dinâmica de ocupação antrópica na BHRP pode ser avaliada pela análise de evolução espaço-temporal do período de 1980 - 2010, uma temporalidade de 30 anos de uso e ocupação destes solos (Figura 3). Observase um incremento de $2.944 \%$ da área ocupada por pastagem cultivada durante esse período, sendo este percentual de $130,4 \%$ para o período subsequente (1990 - 2010). Para cultura agrícola, este incremento foi de 325\% (1990 2010), enquanto que para as classes de cobertura natural houve uma redução de área de 7,2\% (1980 - 1990); 11,8\% (1990 - 2000) e de 9,9\% (2000 - 2010). 


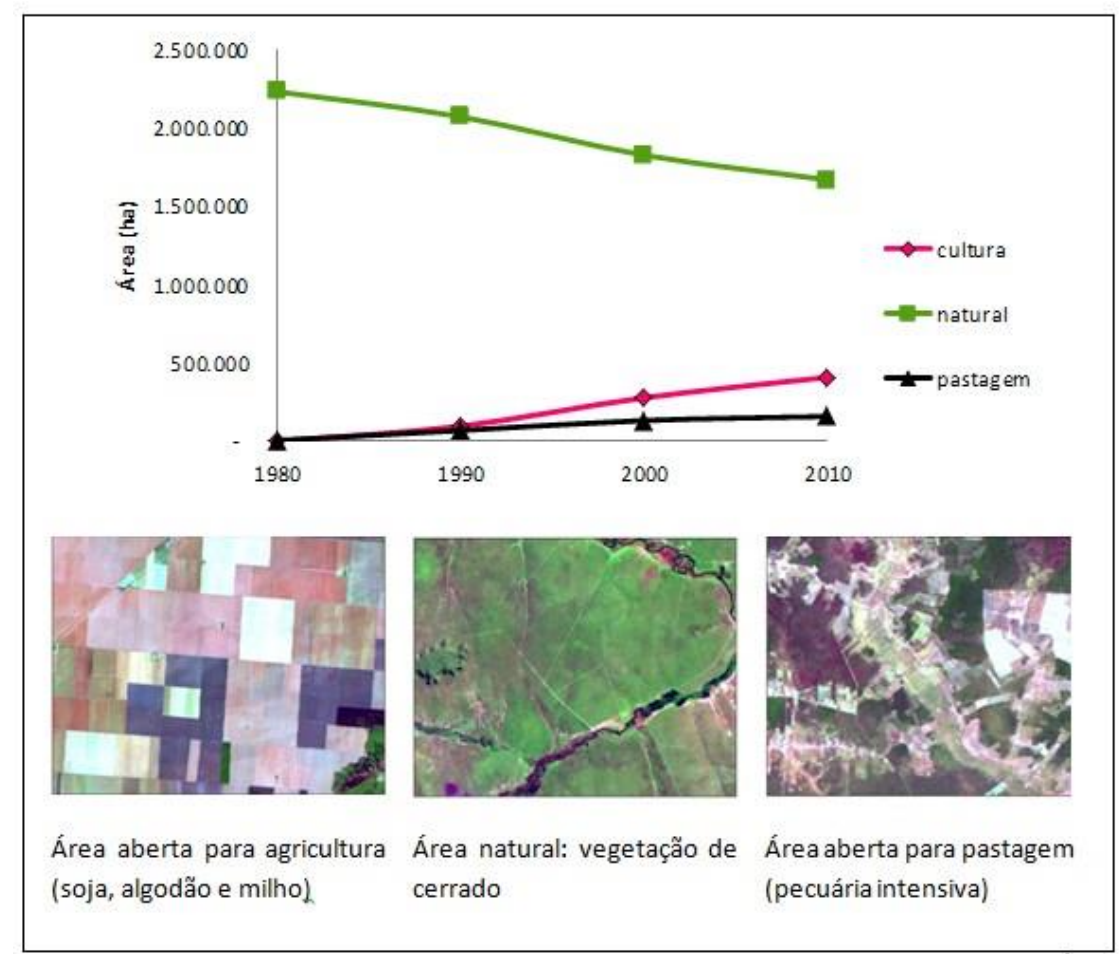

Figura 3 - Evolução temporal do padrão do uso e ocupação dos solos na BHRP.

Estes dados evidenciam a expansão da fronteira agrícola em detrimento da área ocupada pela cobertura vegetal natural, como também elucidam, ainda, o fato de que a pastagem extensiva representa, segundo o processo histórico de uso e ocupação do solo, o primeiro momento da ocupação da bacia. $\mathrm{E}$ que a chegada da fronteira agrícola representou uma mudança na dinâmica de ocupação, expressa por um novo padrão do uso do solo altamente tecnificado, para a produção das commodities agrícolas.

Apesar do uso intensivo dos solos na BHRP, ainda há um grande percentual de cobertura natural a ser monitorado e conservado (Figura 4). $O$ mapeamento de 2010 permitiu inferir que $74,6 \%$ da área da bacia são compostas por cobertura natural, enquanto que $25,4 \%$ estão ocupadas por atividades agropecuárias, sendo 18,3\% representadas pelas culturas agrícolas que estão concentradas na região oeste da bacia, enquanto que as pastagens encontram-se dispersas por toda a bacia. 

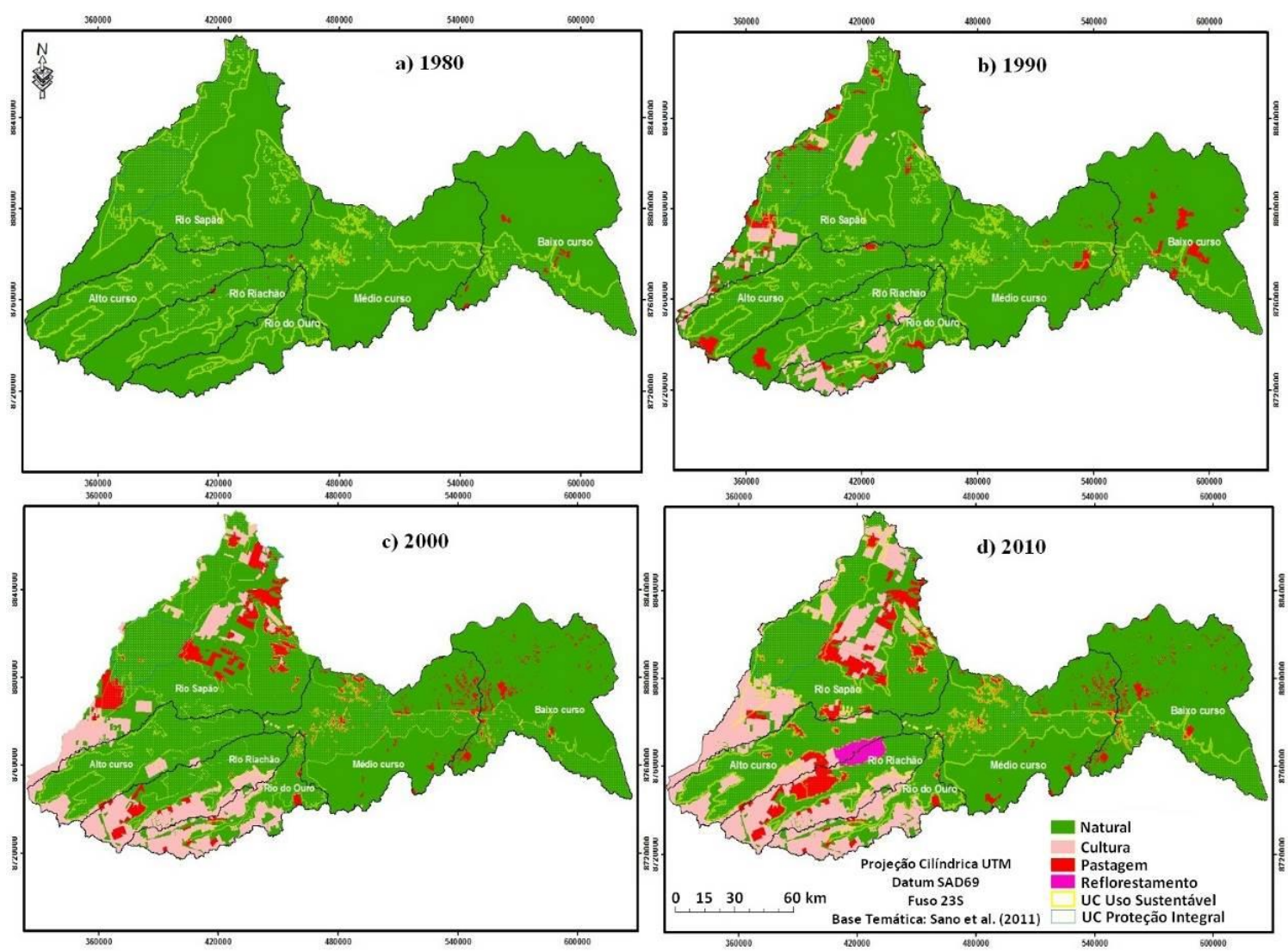

Figura 4 - Mapeamento do uso e ocupação dos solos na BHRP entre os períodos de 1980 a 2010.

Com exceção das sub-bacias Médio Curso (5,3\%) e Baixo Curso $(3,1 \%)$, as demais se encontram bastante comprometidas ambientalmente, segundo a remoção da cobertura natural, sendo a sub-bacia Rio Riachão (61\%), Rio do Ouro $(49,1 \%)$ as mais problemáticas, enquanto que as do Rio Sapão (39\%) e Alto Curso $(28,4)$ encontram-se como perda de cobertura intermediária.

Esta diferença na dinâmica espacial é fortemente marcada pela existência de atributos físicos da bacia que atuam como fator limitante para incorporação de áreas para culturas agrícolas. Desta forma, os maiores percentuais de remanescentes naturais nas sub-bacias Médio e Baixo Cursos se devem pela existência de restrições de atributos do meio físico com impedimentos à conversão do uso do solo, assim como as maiores taxas de conversão da área natural nas sub-bacias Rio Riachão, Rio do Ouro e Rio 
Sapão se deram em função de melhores atributos biofísicos da BHRP, tais como declividade, tipo de solo e pluviosidade.

\subsection{Métricas ao nível da paisagem da BHRP}

Apesar de a BHRP possuir, em 2010, um valor bastante expressivo de remanescentes de cobertura natural $(74,6 \%)$, a mesma está sendo gradualmente transformada para atender demandas crescentes de expansão da principal atividade econômica, a agropecuária, com valores de $18,3 \%$ de commodities agrícolas e de $7,1 \%$ de pastagem. Os resultados das métricas utilizadas para observar os efeitos da expansão da fronteira agrícola sobre a estrutura da paisagem da bacia encontram-se disponíveis na Tabela 3.

A métrica MSI mostrou que a sub-bacia com menor tamanho em área da classe natural foi a que obteve maior valor deste índice. Estes dados são condizentes com o esperado, haja vista que os ambientes de menor retirada da cobertura natural apresentaram forma dos fragmentos mais compactas que aquelas que de maior perda da vegetação. Assim, a sub-bacia de menor área (Rio Riachão) apresentou o maior índice ( $M S I=1,89$ ), enquanto que a subbacia de maior área (Médio Curso) mostrou o menor valor $(\mathrm{MSI}=1,72)$. 
SANTOS, C. A. P.; SANO, E. E.; SANTOS, P. S.

FRONTEIRA AGRÍCOLA E A ANÁLISE DA ESTRUTURA DA PAISAGEM NA BACIA DO RIO PRETO - OESTE DA BAHIA

Tabela 3 - Valores relativos das métricas descritivas da paisagem da BHRP no período de 1980 - 2010.

\begin{tabular}{|c|c|c|c|c|c|c|c|}
\hline Métrica & Ano & Alto Curso & Baixo Curso & Médio Curso & Rio Sapão & Rio do Ouro & Rio Riachão \\
\hline \multirow{4}{*}{ CA (ha) } & 1980 & $155.571,52$ & $264.293,16$ & $166.193,09$ & $509.525,70$ & $119.564,83$ & $167.463,08$ \\
\hline & 1990 & $144.374,41$ & $251.084,64$ & $164.012,38$ & $431.566,95$ & $79.620,11$ & $148.363,62$ \\
\hline & 2000 & $126.332,47$ & $252.885,82$ & $151.456,28$ & $332.374,11$ & $40.635,86$ & $77.685,77$ \\
\hline & 2010 & $86.407,08$ & $252.885,82$ & $149.496,36$ & $248.196,55$ & $36.037,73$ & $38.237,98$ \\
\hline \multirow{4}{*}{ MSI } & 1980 & 1,86 & 1,84 & 1,74 & 1,84 & 1,82 & 1,91 \\
\hline & 1990 & 1,86 & 1,83 & 1,74 & 1,84 & 1,83 & 1,91 \\
\hline & 2000 & 1,85 & 1,82 & 1,73 & 1,84 & 1,81 & 1,90 \\
\hline & 2010 & 1,85 & 1,82 & 1,72 & 1,85 & 1,81 & 1,89 \\
\hline \multirow{4}{*}{ MPFD } & 1980 & 1,45 & 1,47 & 1,47 & 1,45 & 1,46 & 1,46 \\
\hline & 1990 & 1,45 & 1,47 & 1,47 & 1,45 & 1,46 & 1,46 \\
\hline & 2000 & 1,45 & 1,47 & 1,47 & 1,45 & 1,46 & 1,46 \\
\hline & 2010 & 1,45 & 1,47 & 1,47 & 1,45 & 1,46 & 1,46 \\
\hline \multirow{4}{*}{ NP } & 1980 & 2.772 & 5.150 & 10.527 & 4.071 & 1.594 & 1.488 \\
\hline & 1990 & 2.784 & 5.172 & 10.658 & 4.074 & 1.607 & 1.498 \\
\hline & 2000 & 2.801 & 5.184 & 10.411 & 4.118 & 1.671 & 1.548 \\
\hline & 2010 & 2.807 & 5.196 & 10.429 & 4.145 & 1.675 & 1.528 \\
\hline \multirow{4}{*}{ MPS (ha) } & 1980 & 56,12 & 51,32 & 15,79 & 125,16 & 75,01 & 112,54 \\
\hline & 1990 & 51,86 & 48,55 & 15,39 & 105,93 & 49,55 & 99,04 \\
\hline & 2000 & 45,10 & 49,05 & 14,55 & 80,71 & 24,32 & 50,18 \\
\hline & 2010 & 30,78 & 48,67 & 14,33 & 59,88 & 21,52 & 25,02 \\
\hline \multirow{4}{*}{ PSSD (ha) } & 1980 & $1.292,23$ & $2.475,19$ & 348,84 & $5.488,84$ & $2.609,00$ & $3.406,93$ \\
\hline & 1990 & 998,97 & $2.341,62$ & 333,06 & $4.733,33$ & $1.088,16$ & $2.326,41$ \\
\hline & 2000 & 896,48 & $2.324,20$ & 291,13 & $2.384,60$ & 214,52 & 746,11 \\
\hline & 2010 & 588,91 & $2.308,55$ & 285,83 & $1.779,76$ & 181,74 & 147,93 \\
\hline \multirow{4}{*}{ TE (m) } & 1980 & $6.726 .087,13$ & $10.133 .117,67$ & $13.512 .539,77$ & $8.827 .042,38$ & $2.710 .189,61$ & $3.641 .053,34$ \\
\hline & 1990 & $6.799 .128,27$ & $10.020 .136,24$ & $13.616 .745,99$ & $9.242 .207,06$ & $2.909 .593,57$ & $3.743 .594,90$ \\
\hline & 2000 & $6.597 .979,15$ & $9.828 .576,07$ & $12.737 .370,55$ & $9.454 .178,93$ & $2.674 .960,41$ & $3.583 .370,20$ \\
\hline & 2010 & $6.205 .794,82$ & $9.826 .381,48$ & $12.747 .364,12$ & $9.371 .627,56$ & $2.678 .770,37$ & $3.159 .592,57$ \\
\hline \multirow{4}{*}{ ED (m/ha) } & 1980 & 43,23 & 38,34 & 81,31 & 17,32 & 22,67 & 21,74 \\
\hline & 1990 & 47,09 & 39,91 & 83,02 & 21,42 & 36,54 & 25,23 \\
\hline & 2000 & 52,23 & 38,65 & 84,10 & 28,44 & 65,83 & 46,13 \\
\hline & 2010 & 71,82 & 38,86 & 85,27 & 37,76 & 74,33 & 82,63 \\
\hline \multirow{4}{*}{ TCA (ha) } & 1980 & $155.571,52$ & $264.293,16$ & $166.193,09$ & $509.525,70$ & $119.564,83$ & $167.463,08$ \\
\hline & 1990 & $144.374,41$ & $251.084,64$ & $164.012,38$ & $431.566,95$ & $79.620,11$ & $148.363,62$ \\
\hline & 2000 & $126.332,47$ & $254.267,29$ & $151.456,28$ & $332.374,11$ & $40.635,86$ & $77.685,77$ \\
\hline & 2010 & $86.407,08$ & $252.885,82$ & $149.496,36$ & $248.196,55$ & $36.037,73$ & $38.237,98$ \\
\hline \multirow{4}{*}{ TCAI (\%) } & 1980 & 69,31 & 75,44 & 41,21 & 89,77 & 83,72 & 70,72 \\
\hline & 1990 & 67,06 & 74,85 & 41,97 & 88,14 & 74,35 & 63,70 \\
\hline & 2000 & 65,62 & 77,86 & 41,29 & 81,10 & 53,57 & 52,24 \\
\hline & 2010 & 62,76 & 77,72 & 41,09 & 77,97 & 52,31 & 47,06 \\
\hline
\end{tabular}

$\mathrm{CA}=$ área da classe; $\mathrm{MSI}$ = índice médio de forma; MPFD = dimensão fractal média; NP = número de fragmentos; MPS = tamanho médio dos fragmentos; PSSD = desvio padrão do tamanho médio dos fragmentos; TE = soma das bordas; $\mathrm{ED}=$ densidade de bordas; TCA = área central total; e TCAI = índice de área central. 


\section{FRONTEIRA AGRÍCOLA E A ANÁLISE DA ESTRUTURA DA PAISAGEM NA BACIA DO RIO PRETO} - OESTE DA BAHIA

A métrica MPFD complementa a informação derivada do MSI quanto às formas dos fragmentos, ficando notório que os fragmentos das sub-bacias Baixo e Médio Cursos correspondem a fragmentos regulares e com maior tendência a formas compactas (padrão circular), quando comparado com as paisagens das demais bacias. Já as sub-bacias de maior predominância das paisagens agrícolas (Rios Riachão, Rio do Ouro, Rio Sapão e Alto Curso) apresentaram um padrão de fragmentos mais simples ou regular (menor MPFD) e alongados ou recortados (maior MSI).

Perante estes dados, quanto menor a proporção da cobertura natural, maior será a redução da MPFD, devido à maior presença de fragmentos pequenos e que por seguinte ocasiona menor complexidade da paisagem. Esta é uma conclusão que corrobora com a apresentada por Gustafson e Parker (1992) e que, de fato, explica a razão do menor valor desta métrica para as sub-bacias de maior ocupação agrícola.

Com relação à métrica número de fragmentos (NP) foram mapeados na sub-bacia Rio Riachão 1.488 fragmentos para o período inicial de uso e ocupação de seus solos (1980) e 1.528 fragmentos, trinta anos mais tarde, o que expressa um crescimento da fragmentação de 2,7\%. A sub-bacia Rio do Ouro apresentou $5,1 \%$ de crescimento do número de fragmentos de sua paisagem. Apesar de ser a segunda sub-bacia que mais sofreu com o processo de antropização, durante a expansão da fronteira agrícola, esta foi a que mais perdeu habitat ao longo do tempo, perante o surgimento de 81 novos fragmentos.

Quanto à sub-bacia Rio Sapão percebeu-se um comportamento bastante similar às demais, isto é, a presença de baixos números de fragmentos gerados entre os anos de 1980 - 2010 (4.071 e 4.145, respectivamente), um aumento de $1,8 \%$ do processo da fragmentação. Outro baixo número de fragmentos também foi observado para a sub-bacia Alto Curso, durante o período de 1980 - 2010 (1,3\%).

A sub-bacia Médio Curso perdeu 98 fragmentos (-0,9\%), enquanto que a sub-bacia Baixo Curso aumentou em $0,9 \%$ o número de fragmentos durante 0 


\section{FRONTEIRA AGRÍCOLA E A ANÁLISE DA ESTRUTURA DA PAISAGEM NA BACIA DO RIO PRETO} - OESTE DA BAHIA

período de 2010. O significativo número de fragmentos nas sub-bacias de menor antropização (Médio Curso e Baixo Curso) pode ser explicado, segundo Gasparri e Grau (2009), em função de possíveis limitações do meio físico, sobretudo das variações topográficas, determinantes ao favorecimento de uma extensa diversidade de paisagens (RIBEIRO; WALTER, 2008) que, associada a diferentes características fitofisionômicas, edáficas e climáticas, favorecem uma maior riqueza estrutural da paisagem, fruto de uma complexa heterogeneidade de ambientes e não de uma fragmentação da paisagem. Isto porque, de acordo com Lang e Blaschke (2009) esta pode ser uma métrica, tanto reveladora do processo da fragmentação, como também pode se comportar como indicadora de riqueza estrutural da paisagem.

Com relação a CA percebeu-se uma forte tendência de redução desta métrica conforme o aumento da NP, resultado da intensidade do uso e ocupação dos solos na BHRP, podendo também ser entendido como resultado da relação inversa entre o tamanho da área da cobertura natural e o número de fragmentos, visto que, à medida que se aumenta o número de fragmentos se reduz a área da classe, e com isso, intensifica-se o processo da fragmentação (Figura 5).

A antropização da cobertura natural levou à redução de áreas contínuas em fragmentos com áreas de tamanhos mais reduzidos. De acordo com Bezerra et al. (2011) pode ser considerado como um bom indicador do processo da fragmentação, pois as paisagens com maior redução do tamanho dos fragmentos podem ser consideradas como sendo as de maior influência do processo da fragmentação, portanto, as mais perturbadas ambientalmente.

A métrica MPS de todas as sub-bacias apresentou redução nos tamanho dos fragmentos, nas seguintes proporções: -77,8\% (Rio Riachão); -71,3\% (Rio do Ouro); -52,2\% (Rio Sapão); -45,0\% (Alto Curso); -9,2\% (Médio Curso); e 5,2\% (Baixo Curso). Esta redução também se fez presente na métrica PSSD, cujas perdas foram de: -95,6\% (Rio Riachão); -93,0\% (Rio do Ouro); -67,7\% (Rio Sapão); -54,4\% (Alto Curso); -18,1\% (Médio Curso); e -6,73\% (Baixo Curso).

R. Ra'e Ga - Curitiba, v. 36, p.179 - 207 , Abr/2016 
A métrica MPS, em 2010, revelou que os fragmentos remanescentes da cobertura natural são considerados pequenos, com tamanhos oscilando de 14,3 ha (Médio Curso) a 59,9 ha (Rio Sapão). Entretanto, os valores de PSSD indicaram a existência de uma grande variabilidade no tamanho destes, em todas as sub-bacias, com fragmentos muito acima do tamanho médio e variando de 148 ha (Rio Riachão) a 2.308 ha (Baixo Curso). Os tamanhos dos fragmentos encontrados neste estudo sugerem que, mesmo após a instalação da fronteira agrícola, ainda é possível observar a predominância de fragmentos de tamanho significativo. 


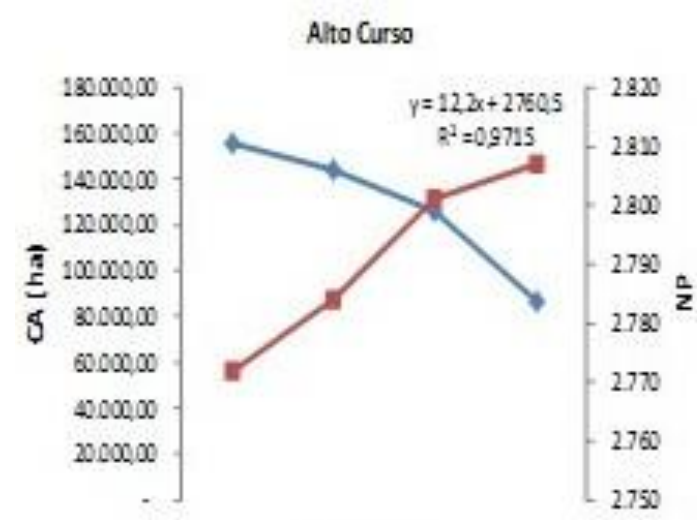

Babro Curso

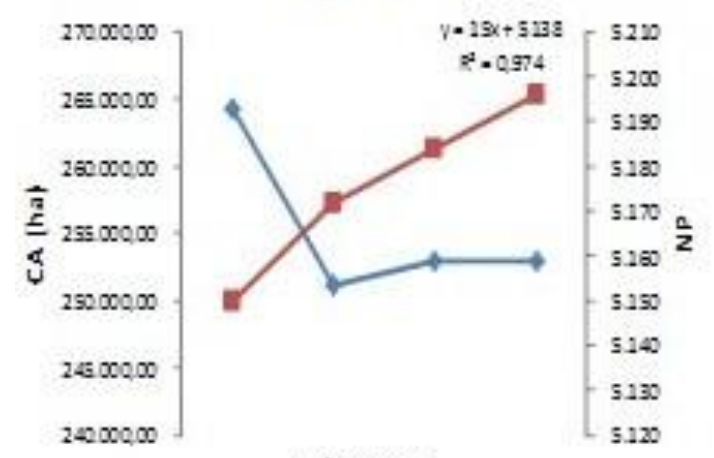

Médio Curso

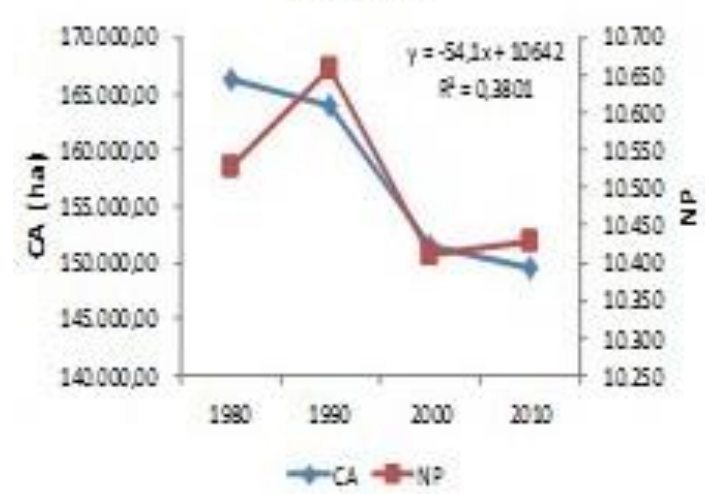

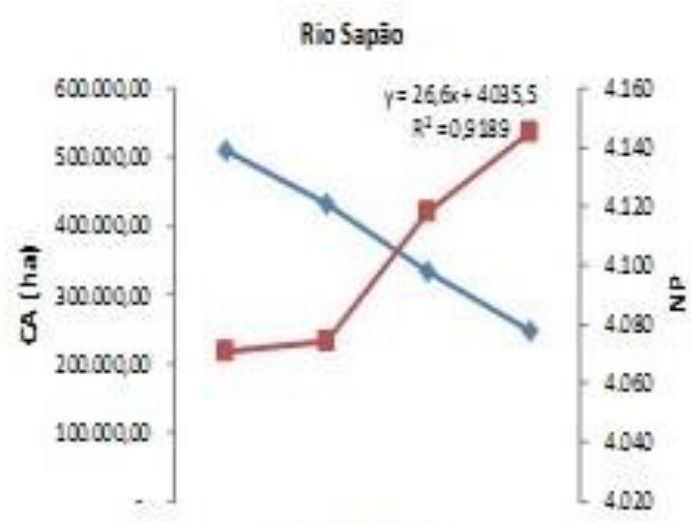

Rio do Ouro

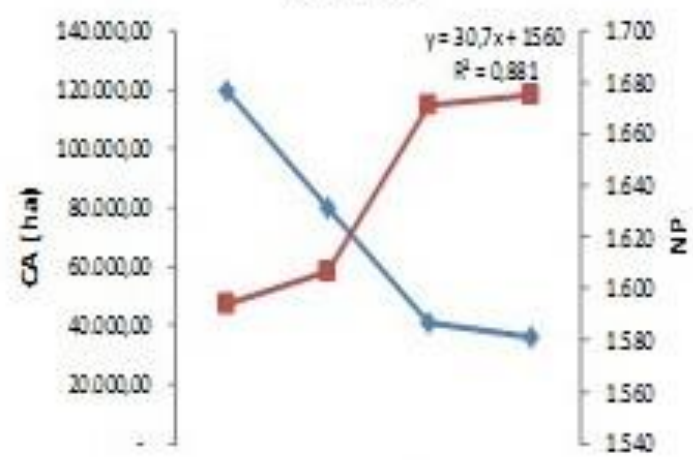

RioRiachão

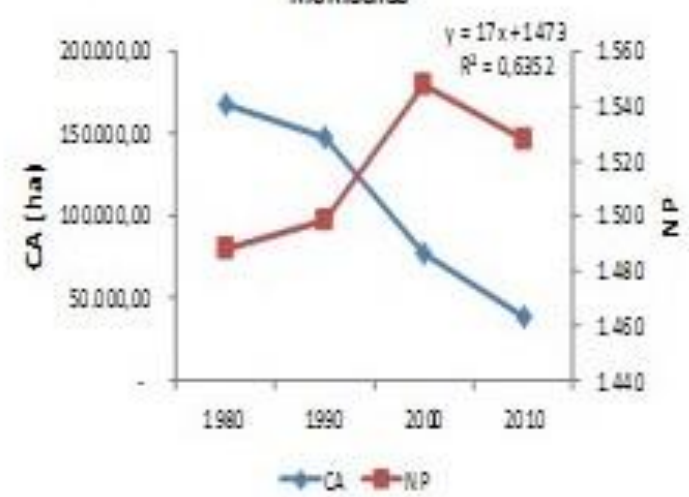

Figura 5 - Relação entre número de fragmentos e a área da classe do fragmento.

A métrica de borda TE revelou que as sub-bacias de menor intensidade de uso do solo e de maior remanescente da cobertura natural, são, entretanto, as que apresentaram maior soma de borda (TE), com valores de $12.747 .364 \mathrm{~m}$ e 9.826.381 $\mathrm{m}$ para as sub-bacias Médio Curso e Baixo Curso, respectivamente, enquanto que os menores valores foram atribuídos às subbacias de maior intensidade do uso do solo (Tabela 3). Atribuiu-se a esta R. Ra'e Ga - Curitiba, v. 36, p.179 - 207 , Abr/2016 


\section{FRONTEIRA AGRÍCOLA E A ANÁLISE DA ESTRUTURA DA PAISAGEM NA BACIA DO RIO PRETO} - OESTE DA BAHIA

situação, a existência de uma grande mancha da cobertura natural (valores acima de 90\%), associada a uma expressiva heterogeneidade espacial de ocorrência natural, independentemente da disposição espacial das unidades da paisagem da BHRP.

O aumento da soma total de borda implica no crescimento da densidade de bordas (METZGER; DECAMPS, 1997; SAITO et al., 2011). Assim, à medida que as áreas de cobertura natural foram sendo subtraídas pelo avanço das ocupações agrícolas, aumentou-se o efeito de borda por meio da densidade de borda (ED). Ao realizar a análise temporal (1980 - 2010), chegou-se à assertiva de que o crescimento da ED foi maior para as sub-bacias Rio Riachão (280,1\%), Rio do Ouro (227,9\%), Rio Sapão $(118,0 \%)$, Alto Curso $(66,1 \%)$ e menor para a Médio Curso (4,9\%) e Baixo Curso $(1,4 \%)$.

Os fragmentos com maior efeito de borda apresentaram redução da área central (TCA), influenciando negativamente na qualidade estrutural do ecossistema ao longo do tempo (Tabela 3). A área central de um fragmento é afetada, de forma direta, pelas métricas de forma e de borda. Por esta razão, é conhecida como sendo o melhor indicador de qualidade de um fragmento, de acurácia maior do que a própria área total (MACGARICAL; MARKS, 1995). A sub-bacia mais comprometida foi a do Rio Riachão, cujo valor original de TCA (1980) era de 167.463 ha e foi reduzida para 38.238 ha, uma perda de área de $77,2 \%$. Outra sub-bacia que sofreu expressiva redução foi a do Rio de Ouro (- 69,8\%), seguidos por Rio Sapão (- 51,3\%), Alto Curso (- 44,5\%), Médio Curso $(-10,0 \%)$ e, por fim, a Baixo Curso $(-4,3 \%)$.

Ao se realizar uma análise temporal da contribuição do efeito da borda sob a área central do fragmento, ou seja, relação borda/área dos fragmentos percebeu-se que as sub-bacias Alto Curso, Baixo Curso e Médio Curso apresentaram mais TCA que TE, apesar da sub-bacia Alto Curso demonstrar uma maior possibilidade de redução da área central em tempos futuros. E que as sub-bacias de maior intensidade do uso do solo (Rio Sapão, Rio do Ouro e Rio Riachão) revelaram uma maior proporção de TE que TCA, com tendências de redução desta última métrica, à medida que a transformação da paisagem é 


\section{FRONTEIRA AGRÍCOLA E A ANÁLISE DA ESTRUTURA DA PAISAGEM NA BACIA DO RIO PRETO} - OESTE DA BAHIA

intensificada por atividades agropecuárias. Estes dados apontaram que as subbacias de maior intensidade do uso do solo sofreram maior interferência do efeito de borda, em função da maior fragmentação da paisagem.

Os dados encontrados nas sub-bacias de maior antropização vão ao encontro de Cemin et al. (2009) cuja defesa incide sobre uma relação não tênue entre as métricas de área com a de borda, sugerindo que uma redução contínua do tamanho do fragmento pode provocar uma situação em que todos os fragmentos das paisagens apresentem habitats com peculiaridades exclusivas de borda e sem presença de área central, o que permite concluir que a área central é inversamente proporcional ao efeito de borda.

A proporção da área ocupada pela área central (TCAl) é essencial para qualificar os fragmentos de cobertura natural existente para cada sub-bacia hidrográfica. À medida que se intensificou o uso do solo na BHRP, reduziu-se a área central total (TCAI), o que implica em perda de qualidade ambiental das paisagens.

Observou-se que cerca de $78,0 \%$ da paisagem do Rio Sapão encontram-se como sendo um habitat de maior qualidade ambiental às diferentes espécies dependentes de área central, mesmo observando que esta foi a terceira sub-bacia que mais perdeu habitat durante os trinta anos de uso e ocupação. Outro habitat de grande valor ambiental foi o da sub-bacia Baixo Curso, cuja proporção de área central em sua paisagem representa $77,7 \%$.

Por outro lado, a Rio Riachão apresentou TCA de 38.238 há, que corresponde a um TCAI de 47,1\%, enquanto que a sub-bacia Rio do Ouro apresentou TCA de 36.078 ha e TCAI de 52.3\%. Já a sub-bacia Alto Curso mostrou valor de TCA de 86.407 ha e um TCAI intacto de $62.8 \%$. Todavia, foi a sub-bacia Médio Curso que apresentou o menor valor de TCAI (TCAI = 41,1\%), para um TCA de 149.496 ha. Isto significa que $58,9 \%$ dos fragmentos desta sub-bacia encontravam-se sobre efeito de borda, haja vista que esta apresentou uma alta relação borda/área (85,3\%).

Isto levou a compreender que a área do fragmento, ou o tamanho médio do fragmento não é suficiente para garantir habitat de valor ambiental, pois 
quanto menos expressiva é a área central, menor é a biodiversidade e equilíbrio do ecossistema ali presente.

\subsection{Estado da fragmentação e qualidade ambiental da BHRP}

Os resultados da aplicação do modelo indicaram que as sub-bacias de maior ocupação agrícola reduziram a qualidade estrutural da paisagem na medida em que se intensificava o uso do solo (Figura 6).

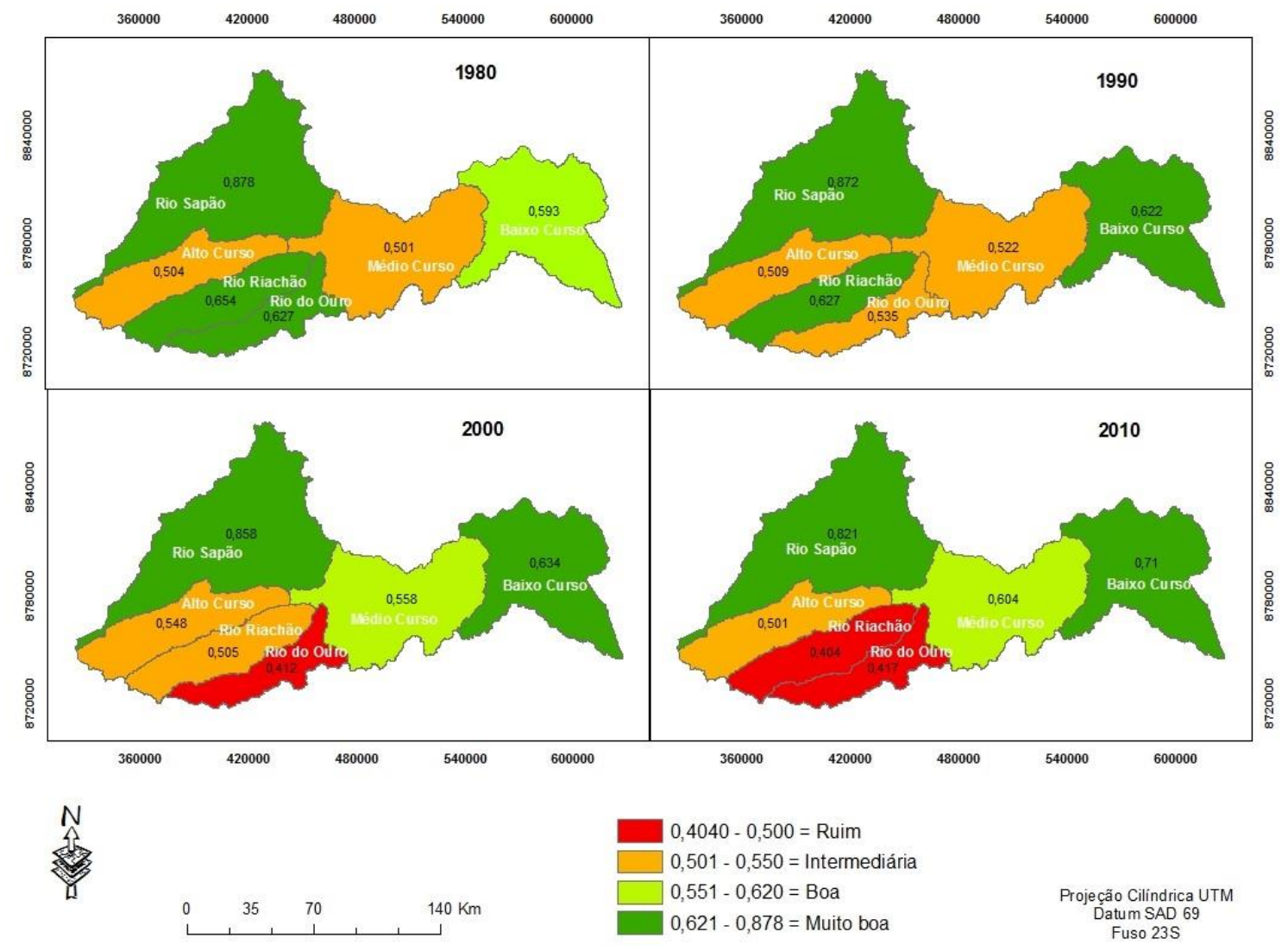

Figura 6 - Índice de qualidade estrutural da paisagem das sub-bacias hidrográficas da BHRP.

Os resultados do IQEP indicaram uma mudança de qualidade estrutural da paisagem da BHRP analisada entre todos os períodos de estudo (1980 - 


\section{FRONTEIRA AGRÍCOLA E A ANÁLISE DA ESTRUTURA DA PAISAGEM NA BACIA DO RIO PRETO} - OESTE DA BAHIA

2010). Desta forma, o modelo permitiu inferir que a sub-bacia Rio Riachão apresentava, antes do período de implantação da fronteira agrícola (1980), uma qualidade estrutural considerada pelo IQEP como "muito boa" $(0,654)$. Entretanto, percebeu-se uma transição para uma qualidade ruim $(0,404)$, durante o período de 2010, uma redução de 38,3\%. O modelo também demonstrou que a alteração da estrutura da paisagem começou a ocorrer a partir de 2000, período marcado pelo acréscimo de 78.667 ha de cultura agrícola, um incremento de $518 \%$ quando comparado com a década anterior (1990). Estes dados corroboram o fato de que o avanço da fronteira agrícola foi relevante para o aumento substancial do processo da fragmentação nesta paisagem.

A sub-bacia Rio do Ouro também saiu de uma condição de qualidade "muito boa" (1980) para uma qualidade intermediária (1990) e ruim durante todo o período restante (2000 - 2010). Percebeu-se uma redução da qualidade equivalente a $15 \%$ (1980 - 1990), a $22,1 \%(1990$ - 2000) e a $1,21 \%$ para 0 período subsequente (2000 - 2010). Estes dados reforçam a hipótese de que a etapa inicial da fronteira agrícola apresentou um efeito negativo maior à qualidade estrutural que nas etapas de expansão da fronteira (2000 - 2010), sobretudo quando a sub-bacia em questão é aquela que apresenta tamanho menor de área (169.839 ha).

Diferentemente do ocorrido na sub-bacia Riachão, a sub-bacia Rio do Ouro representa um dos primeiros vetores de expansão da fronteira agrícola, pois apresenta limite com o município de Riachão das Neves que pertence a uma área de grande potencial agrícola, denominada "Anel da Soja". Por esta razão, os efeitos negativos da antropização nesta sub-bacia se acentuaram mais intensamente sobre o IQEP em apenas cinco anos de uso do solo, visto que a chegada da fronteira agrícola ocorrera em 1985.

Uma situação interessante foi encontrada na sub-bacia do Rio Sapão. Apesar das grandes extensões de áreas ocupadas por culturas agrícolas, ainda há fragmentos naturais importantes quanto à qualidade ambiental, sendo, portanto, a sub-bacia de melhor IQEP durante todo o período analisado. 


\section{FRONTEIRA AGRÍCOLA E A ANÁLISE DA ESTRUTURA DA PAISAGEM NA BACIA DO RIO PRETO} - OESTE DA BAHIA

Ressalta-se que a intensificação do uso do solo resultou numa perda da qualidade estrutural inferior a $7,0 \%$. Tal situação pode ser justificada pelo fato de que esta sub-bacia tem, como característica principal, uma heterogeneidade espacial ressaltada pela presença de fragmentos grandes (tamanhos variando de 60 ha a 1.779 ha), pela significativa área de fragmento remanescente (248.196 ha) e um índice de área central de aproximadamente 78\%.

A sub-bacia Alto Curso apresentou pouca variação do IQEP, resultado do baixo índice de ocupação quando comparada às sub-bacias Rio Riachão, Rio do Ouro e Rio Sapão. Nota-se que em todo o período analisado (1980 2010), O IQEP manteve-se como sendo de qualidade intermediária. Obviamente que esta situação ambiental da sub-bacia é dependente de características estruturais da paisagem, bem como do nível de fragmentação associado a algum grau de modernização.

Com relação às sub-bacias com maiores porcentagens de remanescente natural, a sub-bacia Baixo Curso apresentou alterações na qualidade estrutural da paisagem apenas em 1980. Nesse ano e de acordo com IQEP, a paisagem apresentava boa qualidade estrutural. Ressalta-se que este foi o período de algum grau de modernização agropecuária para esta sub-bacia. No período de 1990 - 2010, a ocupação antrópica permaneceu estável, sem registro de crescimento, consequentemente, sem demanda de modernização agropecuária, o que explica os baixos valores de IMA. Tal realidade conduziu a paisagem um incremento de $20 \%$ do IQEP, o que significa uma condição de qualidade muito boa (1980 - 2010). Este comportamento leva à assertiva de que a conversão de área natural para pastagem cultivada não influenciou o padrão estrutural da paisagem desta sub-bacia, haja vista que o mesmo período representou um incremento na antropização pela pecuária em torno de $350 \%$.

Resultado similar foi encontrado na sub-bacia Médio Curso, a qual mostrou um acréscimo de $21,0 \%$ do IQEP durante todo o período de ocupação. Estes dados, além de evidenciarem uma forte relação entre a cobertura natural e a qualidade estrutural da paisagem, também denotam a realidade de não 


\section{FRONTEIRA AGRÍCOLA E A ANÁLISE DA ESTRUTURA DA PAISAGEM NA BACIA DO RIO PRETO} - OESTE DA BAHIA

serem áreas prioritárias à expansão da fronteira agrícola, por apresentarem limitações do meio físico natural (declividade, por exemplo).

Foi possível constatar a evolução temporal das variáveis NP, MPS, TE, ED e TCAI na medida em que se aumenta o uso e ocupação do solo, o que implica dizer que quanto mais antropizada a bacia, maior é a susceptibilidade à fragmentação da paisagem. Por esta razão, NP, TE e ED que eram menos significativos em 1980, começaram a apresentar-se como excelente indicador da mudança estrutural da paisagem frente ao avanço da fronteira agrícola. Esta situação também foi verificada para TCAI, ressaltando a importância não só do tamanho do fragmento na paisagem, como do percentual de suporte das espécies dependentes de área, na medida em que mais áreas naturais vão sendo incorporadas pelo agronegócio.

Por outro lado, durante o período de 1980 - 2010, as sub-bacias de melhor IQEP (Baixo Curso e Rio Sapão) apresentaram forte correlação positiva com TCAI, TCA, PSSD, MPS e CA, diferentemente das sub-bacias de menor qualidade estrutural que demonstraram correlação positiva, sobretudo com ED (Rio Riachão e Rio do Ouro). Isto significa que o aumento da antropização nesta paisagem provocou maior efeito de borda aos fragmentos remanescentes, o que justifica o aumento da intensidade da correlação ao longo dos trinta anos de uso e ocupação dos solos da BHRP.

Além disso, à medida que se aumentou o uso dos solos, reduziu-se a complexidade (representado pela dimensão fractal) e aumentou-se a regularidade dos fragmentos (índice médio de forma). Assim, as sub-bacias com paisagens agrícolas, ao longo do tempo, mostraram fragmentos com valores baixos de MDI e valores altos de MSI. As sub-bacias Médio Curso e Baixo Curso apresentaram fragmentos com valores altos de MDF (maior complexidade) e com valores baixos de $\mathrm{MSI}$ (menor regularidade).

De forma análoga, é possível identificar a perda do tamanho dos fragmentos nas sub-bacias pós-1980, especialmente para o Rio do Ouro. Fica claro que, com a redução do tamanho dos fragmentos, perde-se a heterogeneidade da paisagem (menor variação do PSSD) e, com isso, 


\section{FRONTEIRA AGRÍCOLA E A ANÁLISE DA ESTRUTURA DA PAISAGEM NA BACIA DO RIO PRETO} - OESTE DA BAHIA

aumenta-se a necessidade de áreas centrais intactas, a fim de garantir área de habitat efetivamente útil ao abrigo de espécies sensíveis ao efeito de borda. A perda de área $(\mathrm{CA})$, além de ter provocado a redução do tamanho do fragmento (MPS), conduziu à paisagem menor heterogeneidade e, consequentemente, ao aumento de área sob efeito de borda, tornando-a menos resistente a quaisquer distúrbios ou perturbações ambientais.

As sub-bacias de menor qualidade ambiental apresentam características como: redução significativa de área natural, fragmentos menores, menor percentual de área central e, sobretudo, com maior incremento de bordas à medida que se intensificava o uso dos solos, mediante a adoção de maior padrão tecnológico (IMA). As sub-bacias que mantiveram seu status ambiental possuem valores significativos de CA, TCAI, MPS e PSSD e menor exposição ao efeito de borda. Portanto, os dados apresentados sugerem que as alterações do padrão estrutural da paisagem seguiram a mesma dinâmica de uso e ocupação do solo de cada sub-bacia hidrográfica pertencente à BHRP.

\section{CONSIDERAÇÕES FINAIS}

O processo da fronteira agrícola no Oeste da Bahia, a partir de 1985, provocou significativas mudanças na estrutura da paisagem, ao longo do tempo e do espaço, com perda de área natural e fragmentação da paisagem, segundo uma dinâmica de uso e ocupação dos solos.

As áreas mais planas das sub-bacias foram intensamente ocupadas com geração de paisagens com fragmentos de tamanho médio à gradualmente menor. Assim, a velocidade da perda de habitat e da fragmentação variou conforme o aspecto natural da paisagem, visto que áreas de menor efeito da declividade, ou seja, planas, foram também as áreas de maior intensidade destes processos.

O modelo adotado possibilitou distinguir as sub-bacias que tiveram influência direta e intensa do avanço antrópico sob a configuração espacial da paisagem. Nesta linha, as sub-bacias Rio Riachão e Rio do Ouro apresentaram significativo comprometimento do padrão estrutural, mediante a redução do 
IQEP, portanto são as mais susceptíveis à fragmentação da paisagem, em função da maior contribuição do efeito da borda sob a área central do fragmento.

Por outro lado, as sub-bacias Baixo Curso e Rio Sapão apresentaram forte correlação positiva com TCAI, TCA, PSSD, MPS e CA, ou seja, consideradas de melhor qualidade estrutural, portanto maior IQEP.

O modelo permitiu ainda observar a grande sensibilidade do IQEP, sobretudo das métricas de área, área central e de borda, o que evidencia a existência de fragmentos de tamanhos menores, de menor conectividade, com maior efeito de borda e com redução de abrigo de espécies dependentes de áreas centrais.

As alterações do padrão estrutural da paisagem seguiram a mesma dinâmica de uso e ocupação do solo de cada sub-bacia hidrográfica pertencente à BHRP.

\section{REFERÊNCIAS}

ALVES, R. R.; BRASIL, J.; MEIRA, S. A.; FEITOSA, G. D. Fragilidade ambiental na bacia hidrográfica do rio Preto - Oeste da Bahia. In: MONDARDO, M. L. (Org.) Espaços agrários e meio ambiente: Bahia, Bahias. Rio de Janeiro: Ponto da Cultura, 2011. n.7, p. 126 - 146.

ASBJORNSEN, H.; ASHTON, M. S.; VOGT, D. J.; PALACIOS, S. Effects of habitat fragmentation on the buffering capacity of edge environments in a seasonally dry tropical oakforest ecosystem in Oaxaca, Mexico. Agriculture, Ecosystems and Environment, Amsterdan, v.103, p.481-495, 2004.

BERTRAND, G. Paisagem e geografia física global. Esboço metodológico. Caderno de Ciências da Terra, São Paulo, v.13, p.1-27, 1968.

BEZERRA, C. G.; SANTOS, A. R.; PIROVANI, D. B.; PIMENTEL, L. B.; EUGENIO, F. C. Estudo da fragmentação florestal e ecologia da paisagem na sub-bacia hidrográfica do córrego Horizonte, Alegre, ES. Espaço e Geografia, Brasília, v.14, n.2, p.257-277, 2011.

BLASCHKE, T. Landschaftsanalyse und bewertung mit GIS. Methodische Untersuchungen zu Ökosystemforschung und Naturschutz am Beispiel der 
bayerischen Salzachauen, 1997a. In: LANG, S.; BLASCHKE, T. Análise da Paisagem com SIG. São Paulo: Oficina de Textos, 2009. 424p.

CABACINHA, C. D.; CASTRO, S. S. Relationships between floristic diversity and vegetation índices, forest structure and landscape metrics of fragments in Brazilian Cerrado. Forest Ecology and Management, Amsterdan, v. 257, p. 2157-2165, 2009.

CEMIN, G.; PERICO, E.; REMPEL, C. Composição e configuração da paisagem da sub-bacia do Arroio Jacaré, Vale do Taquari, RS, com ênfase nas áreas de florestas. Revista Árvore, Viçosa, v.33, n.4 p.705-711, 2009.

CORRÊA, B. S.; LOUZADA, J. N. C. Bioma cerrado, fragmentação florestal e relações ecológicas com a avifauna. Revista Agrogeoambiental, Pouso Alegre, v.2, n.3, p.57-72, 2010.

FERRAZ, S. F. B.; VETTORAZZI, C. A.; THEOBALD, D. M.; BALLESTER, M. V. R. Landscape dynamics of Amazoniam deforestation between 1984 and 2002 in central Rondônia, Brazil: assessment and future scenarios. Forest, Ecology and Management, Amsterdan, v.204, p.67-83, 2005.

FORMAN, R.; COLLINGE, S. K. Nature conserved in changing landscapes with and without spatial planning. Landscape and Urban Planning, Orlando, v.37, n.1, p.129-135, 1997.

FORMAN, R. T. T.; GODRON, M. Landscape ecology. New York: John Wiley. 1986.

GASPARRI, N. I.; GRAU, H. R. Deforestation and fragmentation of Chaco dry forest in NW Argentina (1972-2007). Forest, Ecology and Management, Amsterdan, v.258, p.913-921, 2009.

GOULART, F. F.; SALLES, P.; SAITO, C. H.; MACHADO, R. B. How do different agricultural management strategies affect bird communities inhabiting a savanna-forest mosaic? A qualitative reasoning approach. Agriculture, Ecosystems and Environment, Amsterdan, v.164, p.114-130, 2013.

GUSTAFSON, E. J.; PARKER, G. R. Relationships between landcover proportion and indices of landascape spatial pattern. Landscape Ecology, Amsterdam, v.7, n.2, p.101-110, 1992.

IBAMA. Instituto Brasileiro do Meio Ambiente e dos Recursos Naturais Renováveis. Relatório Técnico de Monitoramento do Desmatamento no Bioma Cerrado, 2002 a 2008: Dados Revisados. Brasília, 2009. Disponível em: http://siscom.ibama.gov.br/monitorabiomas. Acesso em: 20, junho, 2013. 
LANG, S.; BLASCHKE, T. Análise da paisagem com SIG. São Paulo: Oficina de Textos, 2009.

MCGARIGAL, K.; MARKS, B. J. FRAGSTATS: spatial patterns analysis program for quantifiying landscape structure. Portland: USDA, Forest Service, Pacific Northwest Research Station. 1995.

METZGER, J. P.; DECAMPS, H. The structural connectivity threshold: an hypothesis in Conservation Biology at the landscape scale. Acta Oecologica, Amsterdan, v.18, n.1, p.1-12, 1997.

MIYAMOTO, A., SANO, M. The influence of forest management on landscape structure in the cool-temperate forest region of central Japan. 2008. In: SANO, M.; MIYAMOTO, A.; FURUYA, N.; KOGI, K. Using landscape metrics and topographic analysis to examine forest management in a mixed forest, Hokkaido, Japan: Guidelines for management interventions and evaluation of cover changes. Forest Ecology and Management, Amsterdan, v.257, p. 12081218, 2009.

PÉRICO, E.; CEMIN, G. Caracterização da paisagem do município de Arvorezinha, RS, com ênfase na dinâmica dos fragmentos florestais, por meio de sistemas de informações geográficas (SIGs). Scientia Forestales, Piracicaba, n.70, p.9-21, 2006.

RIBEIRO, J. F.; WALTER, B. M. T. As principais fitofisionomias do bioma Cerrado. In: SANO, S. M.; ALMEIDA, S. P.; RIBEIRO, J. F. C. Cerrado, Ecologia e Flora. Planaltina: Embrapa Cerrados, Brasília: Embrapa Informação Tecnológica, v.1, p.151-1999, 2008.

SAITO, E. A.; FONSECA, L. M. G.; ESCADA, M. I. S.; KORTING, T. S. Efeitos da mudança de escala em padrões de desmatamento na Amazônia. Revista Brasileira de Cartografia, Brasília, n.63, v.3, p.401-414, 2011.

SANO, M.; MIYAMOTO, A.; FURUYA, N.; KOGI, K. Using landscape metrics and topographic analysis to examine forest management in a mixed forest, Hokkaido, Japan: Guidelines for management interventions and evaluation of cover changes. Forest Ecology and Management, Amsterdan, v.257, p.12081218, 2009.

SANO, E. E.; SANTOS, C. C. M.; SILVA, E. M.; CHAVES. J. M. Fronteira agrícola do Oeste baiano: considerações sobre os aspectos temporais e 
ambientais. São Paulo, UNESP, Geociências, São Paulo, v.30, n.3, p.479-489, 2011.

SHAO, G.; WU, J. On the accuracy of landascape pattern analysis using remote sensing data. Landscape Ecology, Amsterdan, v. 23, p. 505-511, 2008.

TROLL, C. Geoecology and biogeography. Geoforum, Amsterdan, v.8, p.4346, 1971.

TURNER, M. G. Landscape Ecology: What is the state of the science? Annual Review of Ecology, Evolution, and Systematics, United States, v.36, p.319344, 2005.

VALE, R. M. C.; REIS, S. L. S. A bacia hidrográfica do Rio Preto: repercussões ambientais de um modelo agroeconômico industrial. In: SANTOS, C. C. M.; VALE, R. M. C. (Orgs). Oeste da Bahia: Trilhando velhos e novos caminhos do Além São Francisco. Feira de Santana: Editora UEFS, 2012. n.4, p. 227 269.

WALZ, U. Landscape structure, landscape metrics and biodiversity. Living Reviews in Landscape Research, Germany, v.5, n.3, p.5-16, 2011.

WILSON, T. L.; JOHNSON, E. J.; BISSONETTE, J. A. Relative importance of habitat area and isolation for Bird occurrence patterns in a naturally patchy landscape. Landscape Ecology, Amsterdan, v. 24, p. 351-360, 2009. 